\title{
Inhibitory function of parathyroid hormone- related protein on chondrocyte hypertrophy: the implication for articular cartilage repair
}

\author{
Wei Zhang ${ }^{1,2}$, Jialin Chen",2, Shufang Zhang ${ }^{1,2}$ and Hong Wei Ouyang ${ }^{1-3, *}$
}

\begin{abstract}
Cartilage repair tissue is usually accompanied by chondrocyte hypertrophy and osseous overgrowths, and a role for parathyroid hormone-related protein (PTHrP) in inhibiting chondrocytes from hypertrophic differentiation during the process of endochondral ossification has been demonstrated. However, application of PTHrP in cartilage repair has not been extensively considered. This review systemically summarizes for the first time the inhibitory function of PTHrP on chondrocyte hypertrophy in articular cartilage and during the process of endochondral ossification, as well as the process of mesenchymal stem cell chondrogenic differentiation. Based on the literature review, the strategy of using PTHrP for articular cartilage repair is suggested, which is instructive for clinical treatment of cartilage injuries as well as osteoarthritis.
\end{abstract}

\section{Introduction}

Articular cartilage injuries and osteoarthritis (OA) are commonly encountered in joint diseases. Current treatments aim at generating hyaline-like repair tissue with a stable, permanent chondrocyte phenotype. However, the repair tissue is often accompanied by chondrocyte hypertrophy and bony outgrowths, in particular with respect to bone marrow-eroding techniques $[1,2]$. The progressive abnormal hypertrophy may result in degradation of the matrix, impairing the function of the repair tissue. A role for parathyroid hormone-related protein (PTHrP) in regulating endochondral ossification by inhibiting chondrocytes from hypertrophy has been

\footnotetext{
*Correspondence: hwoy@zju.edu.cn

'Center for Stem Cell and Tissue Engineering, School of Medicine, Zhejiang

University, Hangzhou, China 310058
}

Full list of author information is available at the end of the article demonstrated. Moreover, the inhibitory effect of PTHrP on expression of hypertrophy-related markers in articular chondrocytes and during chondrogenic differentiation of mesenchymal stem cells (MSCs) has been reported by a number of studies [3-7]. Those findings indicate that PTHrP has potential for cartilage repair through inhibiting chondrocyte hypertrophy.

This review presents, compares and discusses the inhibitory function of PTHrP on chondrocyte hypertrophy in articular cartilage and during the process of endochondral ossification, as well as the process of MSC chondrogenic differentiation. Moreover, a strategy for using PTHrP for articular cartilage repair is suggested.

\section{Chondrocyte hypertrophy}

Chondrocyte hypertrophy is commonly found during both endochondral ossification and the process of articular cartilage repair. The former is a physiological process of bone formation, during which chondrocytes become larger and produce collagen type X (Figure 1A,B). These cells are called hypertrophic chondrocytes (quite different from normal chondrocytes, which secrete and maintain the cartilaginous matrix rich in collagen type II and aggrecan). Hypertrophic chondrocytes mineralize surrounding matrix, secrete vascular endothelial growth factor to induce blood vessel formation, and finally undergo apoptosis. Then osteoblasts fill up the vacancy left by hypertrophic chondrocytes and synthesize bone matrix, a process that results in new bone formation [8]. Because chondrocytes go through a series of orderly changes during endochondral ossification, the cartilage is referred to as 'transient' cartilage. In articular cartilage, hypertrophic chondrocytes usually exist quiescently in calcified layers under the tidemark [9] (Figure 1C,D). The upper healthy articular chondrocytes maintain a stable phenotype and are resistant to hypertrophic differentiation [10]. So articular cartilage is called 'permanent' cartilage, which maintains the structure of functional hyaline cartilage throughout life. Under pathological conditions, however, such as cartilage injuries and OA, chondrocyte hypertrophy can be reactivated in the repair 

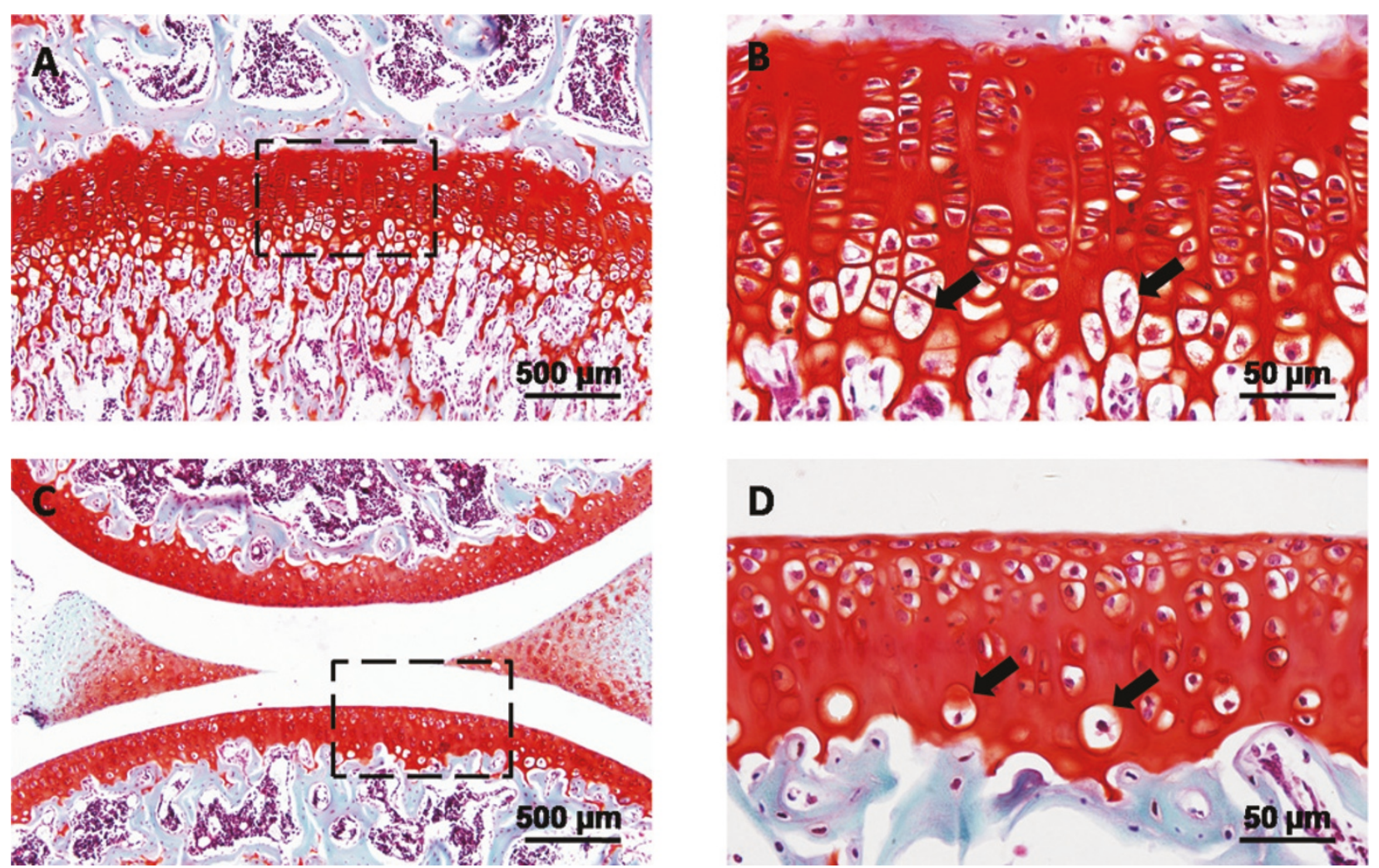

Figure 1. Hypertrophic chondrocytes in normal cartilage of murine knee joint. Microphotographs showing safranin $O$ stained sections. (A,B) Hypertrophic chondrocytes in growth plate cartilage. Boxed area in (A) indicates the region shown in (B). (C,D) Hypertrophic chondrocytes in articular cartilage. Boxed area in (C) indicates the region shown in (D). Note the sites of normal hypertrophic chondrocytes (arrows). Scale bars: $500 \mu \mathrm{m}(\mathrm{A}, \mathrm{C}) ; 50 \mu \mathrm{m}(\mathrm{B}, \mathrm{D})$.

process (Figure 2). The normal articular chondrocytes thus enter hypertrophic differentiation, resembling the process of endochondral bone formation [11,12], which can cause the upper cartilage to become calcified and a relatively thin repair tissue to be formed [1,9]. Hypertrophic chondrocytes in endochondral ossification and cartilage repair tissue show similar characteristics, like the production of collagen type $\mathrm{X}$ [13] and matrix metalloproteinase 13 (MMP-13) [14], promoting degradation of the cartilage matrix. The close link between aberrant hypertrophy and the inferior quality of cartilage repair tissue indicates that chondrocyte hypertrophy might be a potential therapeutic target to improve cartilage repair.

\section{Biology of PTHrP and its correlation with chondrocyte hypertrophy Biology of PTHrP}

PTHrP is a protein member of the parathyroid hormone (PTH) family. It was first identified as a factor required for humoral hypercalcemia of malignancy [15]. PTHrP has been found in many tissues - not only in highabundance sites such as breast, hair follicles and cartilage, but also in previously unrecognized sites, including enthesis and periosteum [16]. PTHrP is a 141 amino acid polypeptide, and most of its biological functions are mediated by its amino terminus, such as the effect on cartilage [17]. Its homolog, parathyroid hormone (PTH), has the same amino-terminal 34-residue peptide fragments as PTHrP, and they thus share a common receptor, parathyroid hormone 1 receptor (PTH1R) [18]. The high similarity in the functional domain makes PTH and PTHrP equally potent at inhibiting chondrocyte hypertrophy, which has been proved by some studies [19-21]. Thus, information obtained from PTH research on hypertrophy inhibition [3,22-24] is also applicable for PTHrP.

\section{The role of PTHrP in endochondral ossification}

During endochondral ossification, chondrocytes move through an orderly differentiation program: periarticular proliferating chondrocytes, columnar proliferating chondrocytes, prehypertrophic chondrocytes and hypertrophic chondrocytes. The role of PTHrP in endochondral ossification was initially studied about 20 years ago. $\mathrm{PTHrP}$ is secreted by periarticular proliferating chondrocytes, while its receptor, PTH1R, is mainly expressed in 


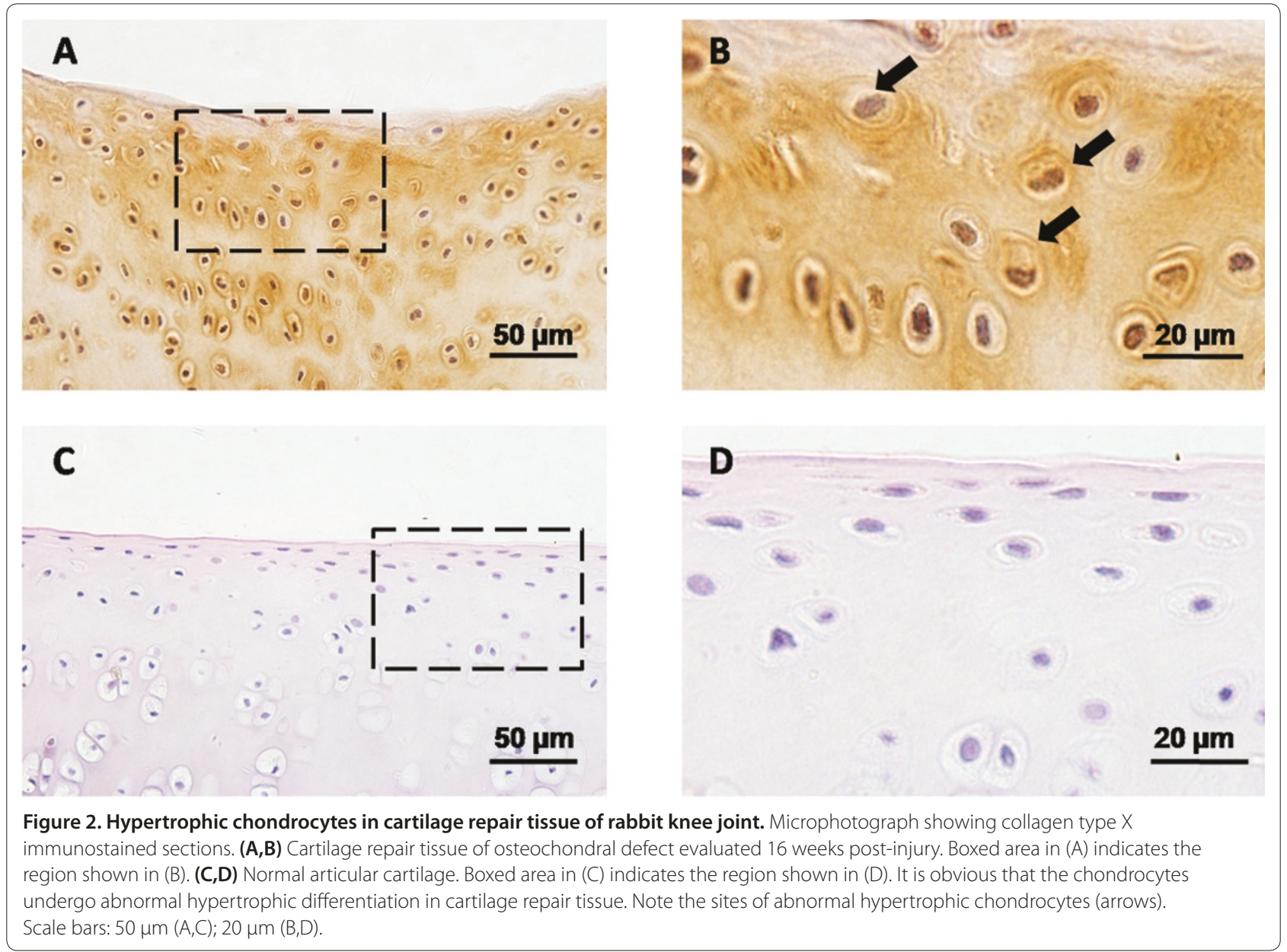

prehypertrophic chondrocytes [25]. When the PTHrP gene was knocked out via homologous recombination in murine embryonic stem cells, the mice died shortly after birth and showed abnormal endochondral bone development [26]. The absence of PTHrP caused diminished chondrocytes and accelerated hypertrophic differentiation leading to premature mineralization of extracellular matrix and apoptosis [27]. Targeted overexpression of PTHrP under the control of the cartilage-specific collagen type II promoter resulted in the opposite effect of chondrodysplasia through delay of the terminal differentiation of chondrocytes, inhibition of apoptosis and disruption of endochondral ossification [28]. Because Bcl-2, an anti-apoptotic protein, lies downstream of PTHrP [29], overexpression of PTHrP increased the expression of Bcl-2, inhibiting apoptotic cell death and disrupting growth plate architecture as well. Similar results were obtained when the PTHrP receptor was manipulated genetically [30,31].

Another important factor involved in endochondral ossification is Indian hedgehog (Ihh), which is expressed by prehypertrophic chondrocytes [32] and acts in conjunction with PTHrP to modulate endochondral ossification. The foundational discovery of the IhhPTHrP regulatory axis was made by Vortkamp and colleagues in 1996 [33]. They found that Ihh stimulated proliferating chondrocytes to produce PTHrP, which in turn accelerated the proliferation of periarticular cells and prevented the onset of chondrocyte hypertrophy, finally keeping chondrocytes in a proliferating state. This negative feedback loop regulates the balance between proliferation and maturation of chondrocytes, ensuring orderly bone formation [33].

The prevailing paradigm - Ihh is mediated by PTHrP to regulate chondrocyte hypertrophy indirectly (it is also the best characterized regulatory function of PTHrP) gained wide acceptance for more than a decade until Kobayashi and colleagues [34] and Mak and colleagues [35] made a breakthrough. Using PTHrP and Ihh mutant mice, Kobayashi and colleagues found that decreasing or enhancing Ihh caused delayed or accelerated periarticular chondrocyte differentiation and reduced or increased the length of the columnar region, respectively, with these effects remaining unchanged regardless of whether 
PTHrP signaling was maintained or disrupted. Therefore, they concluded that Ihh could stimulate periarticular chondrocyte differentiation and cause elongation of the columnar region independent of PTHrP [34]. Based on their results, Mak and colleagues further revealed a novel role of Ihh in regulating chondrocyte hypertrophy without the influence of PTHrP. During endochondral bone formation, PTHrP-dependent Ihh signaling inhibiting chondrocyte hypertrophy is dominant, thereby obscuring the promoting effect of PTHrP-independent Ihh signaling [35] (Figure 3A). Moreover, they speculated that canonical Wnt and bone morphogenetic protein (BMP) signaling may contribute to this non-canonical pathway as well [35].

Besides Ihh, PTHrP can be regulated by other factors as well. Amano and colleagues [36] reported that Sox9 family members inhibited the late stages of endochondral ossification by up-regulating the expression of PTHrP. Human MSCs transfected with the SOX9 gene exhibited enhanced PTHrP expression together with reduction of hypertrophic markers [37]. However, the regulatory effect of SOX9 on expression of PTHrP differed depending on the target organs in vivo [38]. It has also been welldemonstrated by in vitro and in vivo studies that insulinlike growth factor 1 (IGF-1) signaling suppresses PTHrP expression, and thus modulates growth plate development [39]. Besides, the canonical Wnt pathway is known to promote chondrocyte hypertrophy via inhibition of PTHrP signaling activity instead of PTHrP expression [40].

So how does PTHrP function to inhibit premature hypertrophy of chondrocytes? The intracellular pathways have not been completely clarified yet. The PTHrP receptor PTH1R is a classical G-protein-coupled receptor, which transduces signals via the $G_{s}$ or $G_{q / 11}$ family and then activates the cAMP/protein kinase A (PKA) or phospholipase C (PLC)/protein kinase C (PKC) pathway [41]. It has been shown that the inhibitory effects of PTHrP preventing precocious chondrocyte hypertrophy are primarily facilitated by the activation of cAMP/PKA signaling downstream [42]. Chondrocyte hypertrophy could be delayed in mice with a PTH1R mutation that specifically interrupted the PLC/PKC pathway but did not affect cAMP/PKA activation [43]. In chimeric mice with disrupted Gnas exon 2 (encoding $\mathrm{G}_{\mathrm{sa}}$ ), chondrocytes prematurely undergo hypertrophy, resulting in a phenotype similar to that of the PTH1R ${ }^{-1-}$ cells [44]. Taken together, PTHrP favors the $\mathrm{G}_{\mathrm{sa}} / \mathrm{cAMP} / \mathrm{PKA}$-dependent signaling pathway to inhibit hypertrophic differentiation. Several studies have focused on the downstream signaling pathways of PKA. Kozhemyakina and colleagues [45] found that protein phosphatase 2A (PP2A), which is activated by PKA, promoted dephosphorylation of histone deacetylase 4 (HDAC4), which was translocated into the nucleus and repressed the activity of MEF2 transcription factors, ultimately attenuating the rate of chondrocyte hypertrophy. Also, Correa and colleagues [46] showed that Zfp521, the zinc finger transcriptional coregulator, interacted with HDAC4 in the nucleus and this complex repressed expression of runx2-mediated target genes. They generated mice with Zfp521 conditionally deleted in chondrocytes, resulting in early hypertrophic transition and reduced growth plate thickness. This phenomenon is similar to that in the $\mathrm{PTHrP} \mathrm{P}^{-/}$and PTH1R $^{-1-}$ mice as well. Their recent research indicated that deletion of Zfp521 from chondrocytes rescued Jansen metaphyseal chondrodysplasia, a disorder caused by a constitutively activating mutation of PTH1R [47]. Furthermore, PTHrP inhibits runx2 expression in chondrocytes via Nkx3.2/Bapx1-mediated repression [48] or cyclin-D1-CDK4-induced phosphorylation and degradation of runx2 and runx3 [49]. All the pathways mentioned above are transduced via the cAMP/PKA pathway. Several studies have also implicated the PLC/PKC pathway in PTHrP's inhibitory function. Chen and colleagues [50] reported that p38 mitogen-activated protein kinase (MAPK) induced the expression of $\mathrm{Bcl}-2$ as well as collagen type X, and PTH1R activation could block p38 MAPK activity, which was mediated by PKC instead of PKA. The above-mentioned pathways are summarized in Figure 3B. Further investigations are needed to improve our understanding of the mechanisms by which PTHrP inhibits chondrocyte hypertrophy.

\section{The role of PTHrP in articular cartilage maintenance}

Based on the well established theory of PTHrP's role in endochondral ossification, researchers have also tried to apply it to articular cartilage to better understand its pathogenetic mechanisms. A few publications demonstrated that PTHrP could regulate articular chondrocytes. In 2008, Chen and colleagues found that PTHrP participated in the maintenance of articular cartilage as it did in growth plate cartilage [51], using a PTHrP-LacZ knockin mouse that can be used to characterize PTHrP gene expression [18]. The PTHrP-producing cells, in both growth plate cartilage and articular cartilage, are derived from the same source, the chondroepiphysis, which is divided by the secondary ossification center into two distinct PTHrP-expressing subpopulations - the chondrocytes of the articular surface and periarticular proliferating chondrocytes of the growth plate [16] - while PTH1R is expressed in the underlying prehypertrophic chondrocytes.

Jiang and colleagues [4] used a co-culture model to evaluate the interaction of chondrocytes derived from different layers of articular cartilage. They demonstrated that PTHrP produced by the superficial or middle layer could block the alkaline phosphatase activity and related 


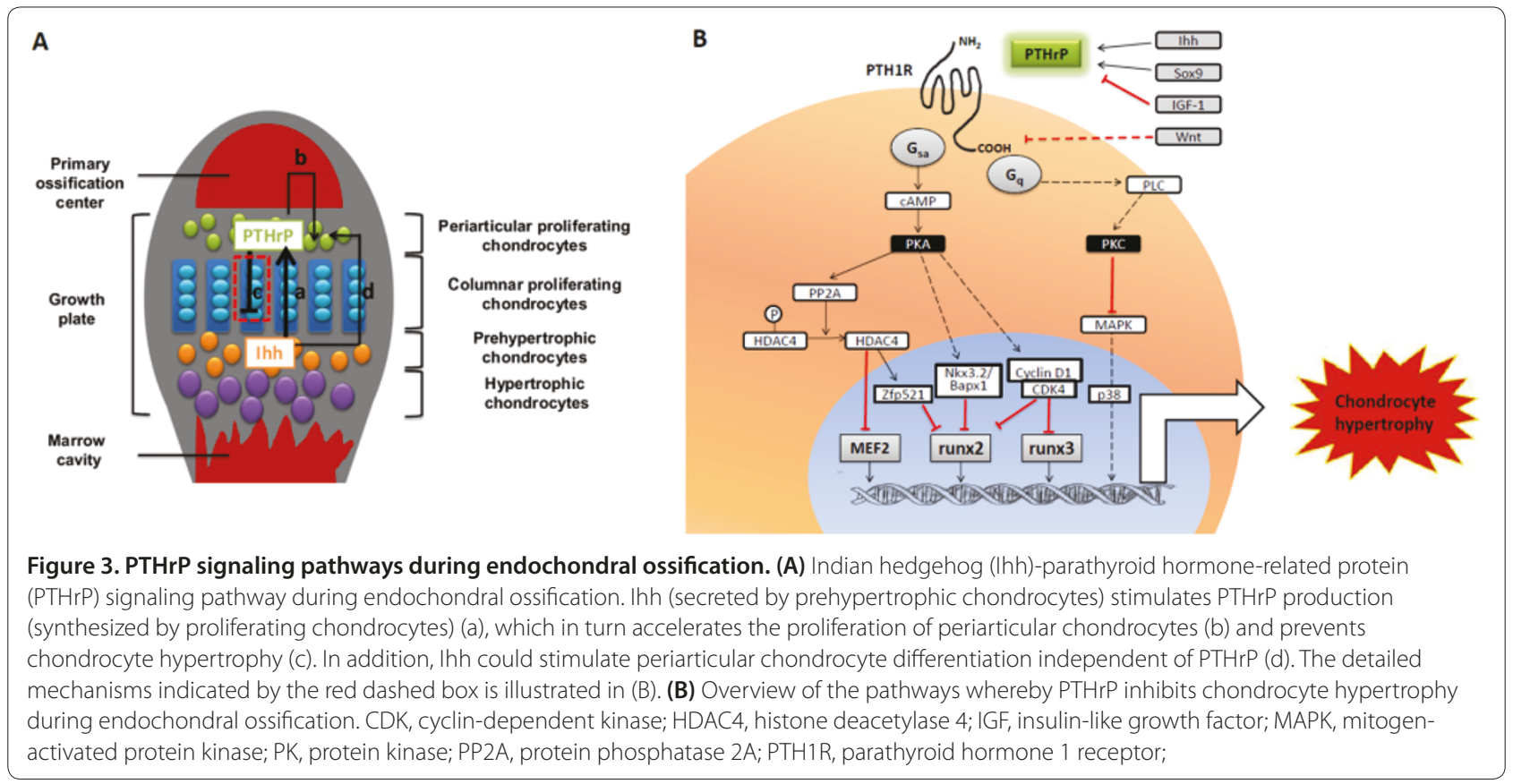

mineralization of chondrocytes from the deep layer. This study provides in vitro evidence that, in healthy articular cartilage, PTHrP secreted by chondrocytes from surface layers inhibits the hypertrophic potential of chondrocytes residing in the deep layer so as to maintain the homeostasis of articular cartilage, but the effect was not confirmed in vivo. More convincing evidence was provided by conditional deletion of PTHrP in midregion articular chondrocytes via growth and differentiation factor 5 (Gdf5) control sequences. After destabilizing medial meniscus, the knock-out mice exhibited severe cartilage degeneration, indicating that PTHrP plays an important role in the physiological regulation of articular cartilage maintenance [52].

Since PTHrP shows inhibitory effects on articular chondrocyte hypertrophy physiologically, the role of PTHrP under pathological conditions was explored as well. It was reported that the expression of PTHrP in articular cartilage was 5.42-fold higher than that of osteophytic chondrocytes, which represents a prototype of cartilage repair tissue [53]. It is probable that the decreased expression of PTHrP is insufficient to inhibit abnormal hypertrophy in repair tissue; therefore, supplement of exogenous PTHrP to diseased cartilage is of great significance. Wang and colleagues [54] transfected bovine articular chondrocytes with human PTHrP (hPTHrP) constructs and applied cyclic tensile strain to induce arthritic changes simultaneously. Overexpression of hPTHrP inhibited cyclic tensile strain-induced collagen type $\mathrm{X}$ expression, suggesting the involvement of PTHrP in resisting mechanical strain-induced hypertrophic-like changes. In another study, human articular chondrocytes were treated with azacytidine to induce terminal differentiation, mimicking the situation in OA [3]. Treatment with exogenous PTH (1-34) (an aminoterminal fragment of PTH) significantly eliminated the increased expression of collagen type $\mathrm{X}$, alkaline phosphatase and Ihh induced by azacytidine. Moreover, when papain-induced OA rats were injected intraarticularly with PTH (1-34) for 5 weeks, the OA cartilage was almost restored to a normal state. It should be noted that, in this research, PTH did not exert any adverse effects on normal chondrocytes or healthy joints, only on OA-affected cartilage. However, studies from Kudo and colleagues [55] showed that bone marrow-derived MSCs transformed from a chondrogenic to a fibroblastic phenotype and osteochondral defects were never covered with cartilage after 4-week PTH (1-84) treatment. This contradiction probably results from the differences in the animal models, injury types and PTH fragments in these two studies. Our group found that the time window for PTHrP administration is of great importance, which could influence chondrogenesis and chondrocyte hypertrophy of repair tissue. More details are given in the next section.

The canonical Ihh-PTHrP pathway has been commonly invoked when discussing results in most publications investigating the mechanisms by which PTHrP regulates articular cartilage $[3,4]$. Chen and colleagues, however, raised a different and challenging possibility $[51,52]$ : in articular cartilage, the master regulatory factor is mechanical loading, rather than Ihh. Such loading would induce expression of PTHrP in the articular chondrocytes 
from the superficial and middle layers, and then transduction of the PTHrP to inhibit terminal differentiation and promote proliferation, a downstream signaling pathway similar to that of endochondral bone formation. It is surprising that the Ihh-PTHrP regulatory axis is uncoupled in articular chondrocytes. In injured and OA cartilage, tensile stiffness in the superficial layer of articular cartilage decreased substantially [56]. It is very likely that the alteration of mechanical loading influences the primary responder, PTHrP, and finally impacts the downstream regulatory system. Although this system has not been fully confirmed, it provides a new idea to study the mechanisms of PTHrP and the pathogenesis of chondrocyte hypertrophy in cartilage repair.

\section{The role of PTHrP in MSC chondrogenic differentiation}

Large and unconfined cartilage injuries are nearly impossible for the eroded articular cartilage to repair by itself. Autologous chondrocyte implantation may be a practical approach to solve this problem and has been applied to the clinical treatment of cartilage defects. However, during the in vitro expansion period for collection of sufficient cells, chondrocytes often undergo rapid dedifferentiation, which limits the clinical application of autologous chondrocyte implantation [57]. MSCs are considered an alternative cell source for cellbased therapies of cartilage injuries. They can be isolated from different tissues, expand rapidly and stably, and differentiate into chondrocytes effectively. It has been reported, however, that induction of chondrogenesis of MSCs in vitro is generally accompanied by unwanted hypertrophic differentiation [58]. Furthermore, ectopic transplantation of MSC pellets in nude mice was followed by calcification and vascular invasion, leading to cartilage phenotypic instability [59]. Because PTHrP exerts inhibitory effects on terminal differentiation of articular cartilage, some researchers proposed that PTHrP may be a candidate to inhibit hypertrophy during MSC chondrogenic dfferentiation as well.

It was reported that co-culture of human MSCs with human articular chondrocytes under chondrogenic induction could promote chondrogenesis and inhibit hypertrophy of the engineered cartilage [60]. Similarly, Fischer and colleagues [5] described that when MSC pellets were induced to differentiate in chondrocyteconditioned medium, hypertrophy was significantly inhibited both in vitro and in the following ectopic transplantation study. Furthermore, when MSCs were cocultured with chondrocytes directly, in vivo calcification was completely inhibited. Further investigations were carried out to identify the chondrocyte-derived soluble factors involved in these effects and PTHrP was found to be the regulator; however, in situ repair studies are needed to confirm this conclusion. In the studies using
PTHrP as a supplement of the chondrogenic medium, MSC pellets differentiated with suppressed hypertrophy in vitro [5-7]. Nevertheless, the effect of PTHrP on chondrogenesis was discrepant. Weiss and colleagues [6] reported an inhibitory effect on collagen type II expression with 1 or $10 \mathrm{ng} / \mathrm{ml}$ PTHrP after 21 days of chondrogenesis, while Kim and colleagues [7] showed collagen type II and SOX9 gene expression increased up to 4-fold in bone marrow-derived MSCs and adipose tissue-derived MSCs when cells were treated with 10 or $100 \mathrm{ng} / \mathrm{ml} \mathrm{PTHrP}$ from the 14th day of culture. This contradiction is probably due to the diverse treatment time or the different fragments and concentrations of PTHrP they used. The above phenomenon was reported in normal cells, whereas Kafienah and colleagues [611] engineered cartilage with MSCs from OA patients. Hypertrophy was remarkably inhibited with PTHrP treatment, though the OA cells were more inclined to terminal differentiation. Moreover, the process of chondrogenesis was not affected by PTHrP. Overall, PTHrP serves as a predominant factor in MSC-based approaches to promote cartilage repair; however, further work is still needed to minimize the undesirable effect on chondrogenesis before clinical use. According to what Weiss and colleagues [6] found, adding $0.1 \mathrm{ng} / \mathrm{ml}$ of PTHrP from day 21 could suppress collagen type $\mathrm{X}$ deposition without any negative effects on chondrogenic differentiation, while higher doses (10 or $100 \mathrm{ng} / \mathrm{ml}$ ) or earlier treatment (from day 0 ) would lead to the suppression of chondrogenesis, valuable information when considering clinical application.

\section{Application of PTHrP for articular cartilage repair}

As described above, it is likely that PTHrP can be used to restrain abnormal hypertrophy in the cartilage repair process. Treatment with PTHrP would consist of two main methods: administration of recombinant protein or gene therapy using genetic manipulation (Figure 4).

\section{Recombinant protein treatment}

Recombinant PTHrP protein used in most studies includes only its functional domains, such as PTHrP (1-34) [3,5,6], to which the PTHrP receptor binds. Experiments have been conducted where MSC pellets have been pre-treated with recombinant human PTHrP (1-34) and then the pellets transplanted subcutaneously into SCID mice [6]. Hypertrophy was inhibited during in vitro chondrogenesis but subsequent in vivo calcification was not repressed. This inefficacy is possibly due to the absence of PTHrP in ectopic transplantation sites, which implies the importance of sustained and sufficient PTHrP for complete inhibition of hypertrophy.

Injection of PTHrP in sites can maintain the working concentration to some extent. Direct delivery of 


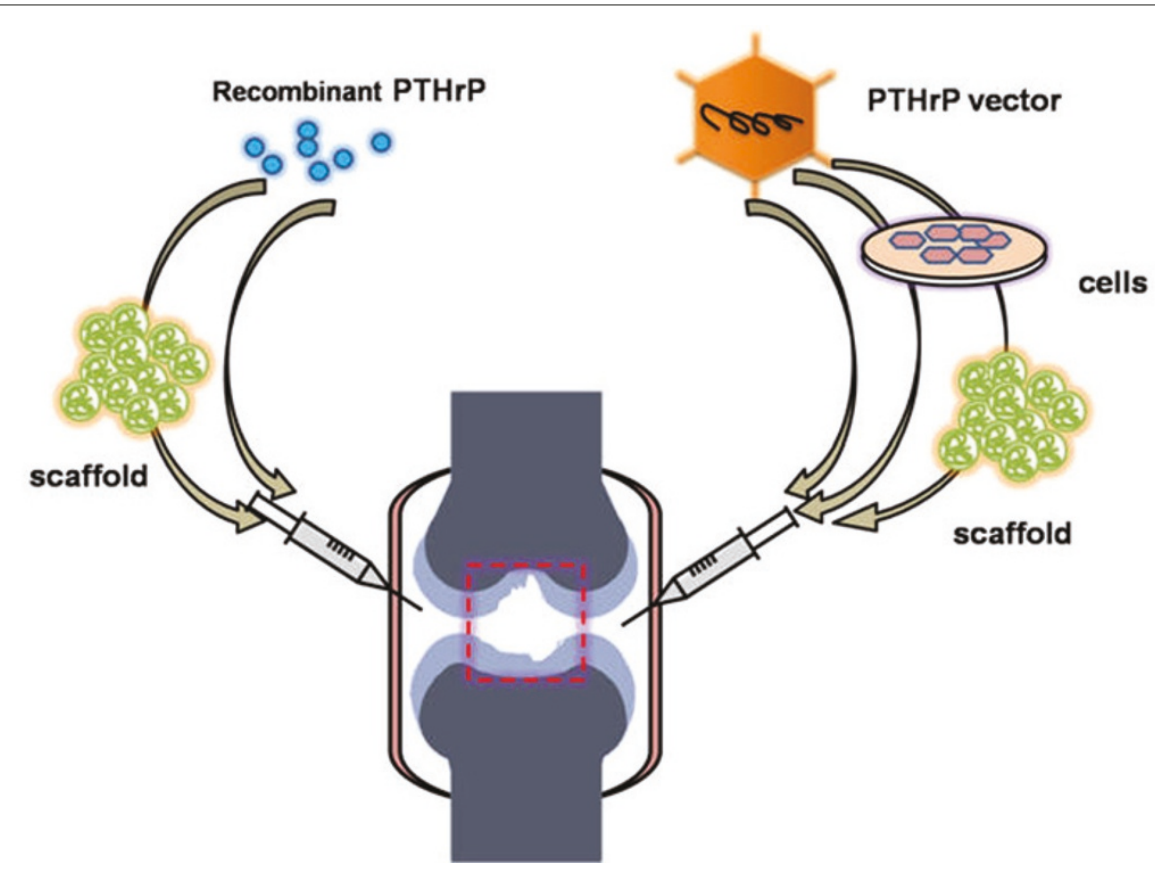

Figure 4. Two different strategies for articular cartilage repair with PTHrP. Left: recombinant parathyroid hormone-related protein (PTHrP)/ peptide can be administered directly or with the aid of biocompatible injectable scaffolds. Right: the PTHrP gene can be delivered by intra-articular injection of gene constructs, or PTHrP-transfected cells alone or combined with injectable scaffolds.

recombinant PTHrP without scaffolds, however, requires frequent injections to compensate for its rapid degradation and removal. Chang and colleagues [3] reported that injection of $10 \mathrm{nM} \mathrm{PTH} \mathrm{(1-34)} \mathrm{intra-articularly} \mathrm{every}$ 3 days delayed progression of $\mathrm{OA}$ in rats. Kudo and colleagues [23] and Mizuta and colleagues [24] demonstrated that constant PTH administration into the joint cavity by an osmotic pump placed subcutaneously avoided the complexities of frequent injection.

Tissue engineering approaches are potent methods for cartilage repair. Biodegradable injectable scaffolds are utilized as a delivery system for the controlled release of PTHrP. Various kinds of materials have been developed to improve local delivery in cartilage tissue engineering, such as collagen-alginate [62]. Release rate and degradation time change with the scaffold materials and structures and an appropriate release system should be chosen according to the release profile of PTHrP, the specificity of the target region, and the actual target effect.

On the other hand, the treatment time must be optimized to avoid the side effects of early or prolonged PTHrP treatment. Mizuta and colleagues [24] demonstrated that a 2-week treatment with PTHrP for fullthickness articular cartilage defects resulted in successful regeneration, while a 4-week treatment resulted in an inferior repair, although the effect on hypertrophy inhibition in repair tissue was not assessed in this study. As mentioned above, our unpublished data indicate that it is quite important to choose a suitable time window for PTHrP administration post-injury. We injected $50 \mu \mathrm{g} / \mathrm{ml}$ hPTHrP (1-40) into rabbit joint cavity once a week at three different time windows: 4 to 6 weeks, 7 to 9 weeks and 10 to 12 weeks after osteochondral defect construction. All rabbits in the three groups were sacrificed 16 weeks post-injury. The results showed that joint cartilage injected at 4 to 6 weeks after osteochondral defect construction exhibited a better morphological and histological appearance than the other groups. The repair tissue with PTHrP injection at 4 to 6 weeks displayed less expression of collagen type $\mathrm{X}$ and other hypertrophic markers than the groups without PTHrP injection or treated over different time windows (unpublished data). These results suggest that 4 to 6 weeks post-injury is a suitable time window to administer PTHrP for osteochondral defect repair in rabbit, but further tests are needed to determine whether this is the case for other animal models or PTHrP concentrations. Kudo and [23] colleagues administrated hPTH (1-84) continuously or intermittently for 2 weeks after creation of full-thickness defects. The repair tissue was found to be fibrous or fibrocartilaginous with continuous treatment after 8 weeks post-injury, while intermittent treatment resulted in restoration of hyaline-like cartilage. Based on the above-mentioned studies, we conclude that short-term and intermittent treatment using PTHrP in the early phase (but not the initiation) after injury may lead to 
superior cartilage repair. However, those pilot studies were done by different groups under different situations, and systematic research must be carried out to determine the conditions leading to the best therapeutic effect.

\section{Gene therapy}

Gene therapy represents another new approach, providing persistent synthesis of required proteins at target sites in vivo. Wang and colleagues [54] generated bovine articular chondrocytes that were transfected with human PTHrP constructs, demonstrating that PTHrP-transfected chondrocytes resisted mechanical strain-induced hypertrophy. This effect was not confirmed by in vivo experiments. Though few studies on PTHrP gene therapy have been conducted, studies focusing on cartilage repair with other genes are numerous, making PTHrP gene transfer feasible and applicable.

PTHrP gene therapy could be carried out in two ways. The PTHrP gene (delivered by adenovirus, lentivirus, adeno-associated virus or other vectors) could be directly introduced to the joint space to affect surrounding cells, such as synovial lining cells, articular chondrocytes and MSCs [63], so that they secrete PTHrP. Alternatively, the PTHrP gene could be transfected into cultured cells, such as chondrocytes, MSCs and other cells, following transplantation of those cells to the target locations [64] for sustained production of PTHrP. In both methods, gene constructs or gene-transfected cells can be pre-mixed with tissue engineered scaffolds before transplantation to guarantee more durable delivery.

However, the problem of unrestrained PTHrP production, similar to excessive administration of recombinant PTHrP mentioned above, could occur with gene therapy, so the level of PTHrP would need to be precisely controlled. According to previous research, $1 \mathrm{ng} / \mathrm{ml}$ PTHrP was suitable for MSC chondrogenesis while higher doses suppressed collagen type II expression [6]. Thus, PTHrP expression should be confined to a certain level for better therapy.

The time window for PTHrP expression also requires consideration. According to our results from protein treatment, PTHrP administration at 4 to 6 weeks post-injury is the optimum time window. Therefore, it would be better to switch the PTHrP gene on during this period. Various kinds of regulatory strategies have been explored to achieve temporal control of transgene expression. Besides the conventional exogenous stimuli, such as tetracycline [65], that have been utilized for years, new types of stimuli, such as light [66] and ultrasound [67], have emerged and can be applied to control of PTHrP expression.

\section{Conclusions and perspectives}

Chondrocyte hypertrophy is found in the process of cartilage repair and endochondral bone formation.
PTHrP has long been recognized as a potent inhibitor of hypertrophic differentiation during endochondral ossification. Pilot studies demonstrated PTHrP's capacity to suppress abnormal hypertrophy in both the articular cartilage and MSC chondrogenic differentiation processes. So, it could be reasoned that PTHrP may potentially inhibit chondrocyte hypertrophy in cartilage repair tissue as well. Like other bioactive factors, therapy with PTHrP could be achieved using recombinant protein or gene manipulation. However, to develop an efficient and applicable way for functional cartilage repair with PTHrP, several key issues need to be further investigated.

First, a suitable PTHrP concentration should be determined. This should be sufficient to inhibit hypertrophy but have no adverse effects on chondrogenesis. The concentration changes depending on the animal model, PTHrP fragments used, administration time, and so on.

Second, the time over which PTHrP functions best should be determined. This should be early, short and intermittent to avoid side effects of earlier or prolonged PTHrP treatment. The release frequency and duration need to be optimized according to practical requirements.

Third, the PTHrP delivery system should be optimized, including the delivery material, methods of recombinant protein injection, as well as methods of PTHrP gene transfer.

Finally, more in vivo studies are necessary to gain more direct evidence on the efficacy of PTHrP on articular cartilage repair and to elucidate the underlying mechanisms more clearly in a variety of animal models.

\section{Abbreviations \\ hPTHrP, human parathyroid hormone-related protein; Ihh, Indian hedgehog; MSC, mesenchymal stem cell; OA, osteoarthritis; PK, protein kinase; PLC, phospholipase C; PTH, parathyroid hormone; PTH1R, parathyroid hormone 1 receptor; PTHrP, parathyroid hormone-related protein.}

\section{Competing interests}

The authors declare that they have no competing interests.

\section{Acknowledgements}

We appreciate Dr Yangzi Jiang and Dr Hua Liu's comments on the manuscript. This work was supported by National Key Basic Research Program (2012CB966600), National Natural Science Foundation of China (81125014, 81071461, J1103603, 31000436), International Science \& Technology Cooperation Program of China (2011DFA32190), Zhejiang Province Grants (Z2100086, 2011C23079)

\section{Author details}

'Center for for Stem Cell and Tissue Engineering, School of Medicine, Zhejiang University, Hangzhou, China 310058. ${ }^{2}$ Zhejiang Provincial Key Laboratory of Tissue Engineering and Regenerative Medicine, Hangzhou, China 310000. ${ }^{3}$ Department of Sports Medicine, School of Medicine, Zhejiang University, Hangzhou, China 310058

Published: 31 August 2012

\section{References}

1. Mithoefer K, Williams RR, Warren RF, Potter HG, Spock CR, Jones EC, Wickiewicz TL, Marx RG: The microfracture technique for the treatment of 
articular cartilage lesions in the knee. A prospective cohort study. J Bone Joint Surg Am 2005, 87:1911-1920.

2. Kreuz PC, Steinwachs MR, Erggelet C, Krause SJ, Konrad G, Uhl M, Sudkamp N: Results after microfracture of full-thickness chondral defects in different compartments in the knee. Osteoarthritis Cartilage 2006, 14:1119-1125.

3. Chang JK, Chang LH, Hung SH, Wu SC, Lee HY, Lin YS, Chen CH, Fu YC, Wang GJ, Ho ML: Parathyroid hormone 1-34 inhibits terminal differentiation of human articular chondrocytes and osteoarthritis progression in rats. Arthritis Rheum 2009, 60:3049-3060.

4. Jiang J, Leong NL, Mung JC, Hidaka C, Lu HH: Interaction between zonal populations of articular chondrocytes suppresses chondrocyte mineralization and this process is mediated by PTHrP. Osteoarthritis Cartilage 2008, 16:70-82.

5. Fischer J, Dickhut A, Rickert M, Richter W: Articular chondrocytes secrete PTHrP and inhibit hypertrophy of mesenchymal stem cells in coculture during chondrogenesis. Arthritis Rheum 2010, 62:2696-2706.

6. Weiss S, Hennig T, Bock R, Steck E, Richter W: Impact of growth factors and PTHrP on early and late chondrogenic differentiation of human mesenchymal stem cells. J Cell Physiol 2010, 223:84-93.

7. Kim YJ, Kim HJ, Im GI: PTHrP promotes chondrogenesis and suppresses hypertrophy from both bone marrow-derived and adipose tissue-derived MSCs. Biochem Biophys Res Commun 2008, 373:104-108.

8. Kronenberg HM: Developmental regulation of the growth plate. Nature 2003, 423:332-336

9. Oegema TJ, Carpenter RJ, Hofmeister F, Thompson RJ: The interaction of the zone of calcified cartilage and subchondral bone in osteoarthritis. Microsc Res Tech 1997, 37:324-332.

10. Binette F, McQuaid DP, Haudenschild DR, Yaeger PC, McPherson JM, Tubo R: Expression of a stable articular cartilage phenotype without evidence of hypertrophy by adult human articular chondrocytes in vitro. J Orthop Res 1998, 16:207-216.

11. Blanke M, Carl HD, Klinger P, Swoboda B, Hennig F, Gelse K: Transplanted chondrocytes inhibit endochondral ossification within cartilage repair tissue. Calcif Tissue Int 2009, 85:421-433.

12. Drissi H, Zuscik M, Rosier R, O'Keefe R: Transcriptional regulation of chondrocyte maturation: potential involvement of transcription factors in OA pathogenesis. Mol Aspects Med 2005, 26:169-179.

13. von der Mark K, Kirsch T, Nerlich A, Kuss A, Weseloh G, Gluckert K, Stoss H: Type $X$ collagen synthesis in human osteoarthritic cartilage. Indication of chondrocyte hypertrophy. Arthritis Rheum 1992, 35:806-811.

14. Reboul P, Pelletier JP, Tardif G, Cloutier JM, Martel-Pelletier J: The new collagenase, collagenase-3, is expressed and synthesized by human chondrocytes but not by synoviocytes. A role in osteoarthritis. J Clin Invest 1996, 97:2011-2019.

15. Suva LI, Winslow GA, Wettenhall RE, Hammonds RG, Moseley JM, DiefenbachJagger $\mathrm{H}$, Rodda CP, Kemp BE, Rodriguez H, Chen EY, et al:: A parathyroid hormone-related protein implicated in malignant hypercalcemia: cloning and expression. Science 1987, 237:893-896.

16. Chen X, Macica CM, Dreyer BE, Hammond VE, Hens JR, Philbrick WM, Broadus AE: Initial characterization of PTH-related protein gene-driven lacZ expression in the mouse. J Bone Miner Res 2006, 21:113-123.

17. Toribio RE, Brown HA, Novince CM, Marlow B, Hernon K, Lanigan LG, Hildreth BE 3rd, Werbeck JL, Shu ST, Lorch G, Carlton M, Foley J, Boyaka P, McCauley LK, Rosol TJ: The midregion, nuclear localization sequence, and $\mathrm{C}$ terminus of PTHrP regulate skeletal development, hematopoiesis, and survival in mice. Faseb J 2010, 24:1947-1957.

18. Pioszak AA, Parker NR, Gardella TJ, Xu HE: Structural basis for parathyroid hormone-related protein binding to the parathyroid hormone receptor and design of conformation-selective peptides. J Biol Chem 2009, 284:28382-28391.

19. Weisser J, Riemer S, Schmidl M, Suva LJ, Poschl E, Brauer R, von der Mark K: Four distinct chondrocyte populations in the fetal bovine growth plate: highest expression levels of PTH/PTHrP receptor, Indian hedgehog, and MMP-13 in hypertrophic chondrocytes and their suppression by PTH (1-34) and PTHrP (1-40). Exp Cell Res 2002, 279:1-13.

20. Riemer S, Gebhard S, Beier F, Poschl E, von der Mark K: Role of c-fos in the regulation of type $\mathrm{X}$ collagen gene expression by PTH and PTHrP: localization of a PTH/PTHrP-responsive region in the human COL10A1 enhancer. J Cell Biochem 2002, 86:688-699.

21. Zerega B, Cermelli S, Bianco P, Cancedda R, Cancedda FD: Parathyroid hormone [PTH(1-34)] and parathyroid hormone-related protein
[PTHrP(1-34)] promote reversion of hypertrophic chondrocytes to a prehypertrophic proliferating phenotype and prevent terminal differentiation of osteoblast-like cells. J Bone Miner Res 1999, 14:1281-1289.

22. Mwale F, Yao G, Ouellet JA, Petit A, Antoniou J: Effect of parathyroid hormone on type $\mathrm{X}$ and type Il collagen expression in mesenchymal stem cells from osteoarthritic patients. Tissue Eng Part A 2010, 16:3449-3455.

23. Kudo S, Mizuta H, Takagi K, Hiraki Y: Cartilaginous repair of full-thickness articular cartilage defects is induced by the intermittent activation of PTH/ PTHrP signaling. Osteoarthritis Cartilage 2011, 19:886-894.

24. Mizuta H, Kudo S, Nakamura E, Takagi K, Hiraki Y: Expression of the PTH/ PTHrP receptor in chondrogenic cells during the repair of full-thickness defects of articular cartilage. Osteoarthritis Cartilage 2006, 14:944-952.

25. Lee K, Deeds JD, Segre GV: Expression of parathyroid hormone-related peptide and its receptor messenger ribonucleic acids during fetal development of rats. Endocrinology 1995, 136:453-463.

26. Karaplis AC, Luz A, Glowacki J, Bronson RT, Tybulewicz VL, Kronenberg HM, Mulligan RC: Lethal skeletal dysplasia from targeted disruption of the parathyroid hormone-related peptide gene. Genes Dev 1994, 8:277-289.

27. Amizuka N, Henderson JE, Hoshi K, Warshawsky H, Ozawa H, Goltzman D, Karaplis AC: Programmed cell death of chondrocytes and aberrant chondrogenesis in mice homozygous for parathyroid hormone-related peptide gene deletion. Endocrinology 1996, 137:5055-5067.

28. Weir EC, Philbrick WM, Amling M, Neff LA, Baron R, Broadus AE: Targeted overexpression of parathyroid hormone-related peptide in chondrocytes causes chondrodysplasia and delayed endochondral bone formation. Proc Natl Acad Sci U S A 1996, 93:10240-10245.

29. Amling M, Neff L, Tanaka S, Inoue D, Kuida K, Weir E, Philbrick WM, Broadus $A E$, Baron $\mathrm{R}: \mathrm{BCl}-2$ lies downstream of parathyroid hormone-related peptide in a signaling pathway that regulates chondrocyte maturation during skeletal development. J Cell Biol 1997, 136:205-213.

30. Schipani E, Langman CB, Parfitt AM, Jensen GS, Kikuchi S, Kooh SW, Cole WG, Juppner $\mathrm{H}$ : Constitutively activated receptors for parathyroid hormone and parathyroid hormone-related peptide in Jansen's metaphyseal chondrodysplasia. NEngl J Med 1996, 335:708-714.

31. Chung UI, Lanske B, Lee K, Li E, Kronenberg H: The parathyroid hormone/ parathyroid hormone-related peptide receptor coordinates endochondral bone development by directly controlling chondrocyte differentiation. Proc Natl Acad Sci U S A 1998, 95:13030-13035.

32. Bitgood MJ, McMahon AP: Hedgehog and Bmp genes are coexpressed at many diverse sites of cell-cell interaction in the mouse embryo. Dev Biol 1995, 172:126-138.

33. Vortkamp A, Lee K, Lanske B, Segre GV, Kronenberg HM, Tabin CJ: Regulation of rate of cartilage differentiation by Indian hedgehog and PTH-related protein. Science 1996, 273:613-622.

34. Kobayashi T, Soegiarto DW, Yang Y, Lanske B, Schipani E, McMahon AP, Kronenberg HM: Indian hedgehog stimulates periarticular chondrocyte differentiation to regulate growth plate length independently of PTHrP. J Clin Invest 2005, 115:1734-1742.

35. Mak KK, Kronenberg HM, Chuang PT, Mackem S, Yang Y: Indian hedgehog signals independently of PTHrP to promote chondrocyte hypertrophy. Development 2008, 135:1947-1956.

36. Amano K, Hata K, Sugita A, Takigawa Y, Ono K, Wakabayashi M, Kogo M, Nishimura R, Yoneda T: Sox9 family members negatively regulate maturation and calcification of chondrocytes through up-regulation of parathyroid hormone-related protein. Mol Biol Cell 2009, 20:4541-4551.

37. Venkatesan JK, Ekici M, Madry H, Schmitt G, Kohn D, Cucchiarini M: SOX9 gene transfer via safe, stable, replication-defective recombinant adenoassociated virus vectors as a novel, powerful tool to enhance the chondrogenic potential of human mesenchymal stem cells. Stem Cell Res Ther 2012, 3:22.

38. Yan YL, Bhattacharya P, He X, Ponugoti B, Marquardt B, Layman J, Grunloh M, Postlethwait JH, Rubin D: Duplicated zebrafish co-orthologs of parathyroid hormone-related peptide (PTHrP, Pthlh) play different roles in craniofacial skeletogenesis. J Endocrinol 2012 [Epub ahead of print].

39. Wang Y, Cheng Z, Elalieh HZ, Nakamura E, Nguyen MT, Mackem S, Clemens TL, Bikle DD, Chang W: IGF-1R signaling in chondrocytes modulates growth plate development by interacting with the PTHrP//hh pathway. $J$ Bone Miner Res 2011, 26:1437-1446.

40. Guo X, Mak KK, Taketo MM, Yang Y: The Wnt/beta-catenin pathway interacts differentially with PTHrP signaling to control chondrocyte hypertrophy and final maturation. PLoS One 2009, 4:e6067. 
41. Fujimori A, Cheng SL, Avioli LV, Civitelli R: Structure-function relationship of parathyroid hormone: activation of phospholipase-C, protein kinase-A and -C in osteosarcoma cells. Endocrinology 1992, 130:29-36.

42. Ionescu AM, Schwarz EM, Vinson C, Puzas JE, Rosier R, Reynolds PR, O'Keefe RJ: PTHrP modulates chondrocyte differentiation through AP-1 and CREB signaling. J Bio/ Chem 2001, 276:11639-11647.

43. Guo J, Chung UI, Kondo H, Bringhurst FR, Kronenberg HM: The PTH/PTHrP receptor can delay chondrocyte hypertrophy in vivo without activating phospholipase C. Dev Cell 2002, 3:183-194.

44. Bastepe M, Weinstein LS, Ogata N, Kawaguchi H, Juppner H, Kronenberg HM, Chung UI: Stimulatory G protein directly regulates hypertrophic differentiation of growth plate cartilage in vivo. Proc Natl Acad Sci U S A 2004, 101:14794-14799.

45. Kozhemyakina E, Cohen T, Yao TP, Lassar AB: Parathyroid hormone-related peptide represses chondrocyte hypertrophy through a protein phosphatase 2A/histone deacetylase 4/MEF2 pathway. Mol Cell Biol 2009, 29:5751-5762.

46. Correa D, Hesse E, Seriwatanachai D, Kiviranta R, Saito H, Yamana K, Neff L, Atfi A, Coillard L, Sitara D, Maeda Y, Warming S, Jenkins NA, Copeland NG, Horne WC, Lanske B, Baron R: Zfp521 is a target gene and key effector of parathyroid hormone-related peptide signaling in growth plate chondrocytes. Dev Cell 2010, 19:533-546.

47. Seriwatanachai D, Densmore MJ, Sato T, Correa D, Neff L, Baron R, Lanske B: Deletion of Zfp521 rescues the growth plate phenotype in a mouse model of Jansen metaphyseal chondrodysplasia. Faseb J 2011, 25:3057-3067.

48. Provot S, Kempf H, Murtaugh LC, Chung UI, Kim DW, Chyung J, Kronenberg HM, Lassar AB: Nkx3.2/Bapx1 acts as a negative regulator of chondrocyte maturation. Development 2006, 133:651-662.

49. Zhang M, Xie R, Hou W, Wang B, Shen R, Wang X, Wang Q, Zhu T, Jonason JH, Chen D: PTHrP prevents chondrocyte premature hypertrophy by inducing cyclin-D1-dependent Runx2 and Runx3 phosphorylation, ubiquitylation and proteasomal degradation. J Cell Sci 2009, 122:1382-1389.

50. Zhen X, Wei L, Wu Q, Zhang Y, Chen Q: Mitogen-activated protein kinase p38 mediates regulation of chondrocyte differentiation by parathyroid hormone. J Biol Chem 2001, 276:4879-4885.

51. Chen X, Macica CM, Nasiri A, Broadus AE: Regulation of articular chondrocyte proliferation and differentiation by indian hedgehog and parathyroid hormone-related protein in mice. Arthritis Rheum 2008, 58:3788-3797.

52. Macica C, Liang G, Nasiri A, Broadus AE: Genetic evidence that parathyroid hormone-related protein regulates articular chondrocyte maintenance. Arthritis Rheum 2011, 63:3333-3343.

53. Gelse K, Ekici AB, Cipa F, Swoboda B, Carl HD, Olk A, Hennig FF, Klinger P: Molecular differentiation between osteophytic and articular cartilage - clues for a transient and permanent chondrocyte phenotype. Osteoarthritis Cartilage 2012, 20:162-171.

54. Wang D, Taboas JM, Tuan RS: PTHrP overexpression partially inhibits a mechanical strain-induced arthritic phenotype in chondrocytes. Osteoarthritis Cartilage 2010, 19:213-221.

55. Kudo S, Mizuta H, Otsuka Y, Takagi K, Hiraki Y: Inhibition of chondrogenesis by parathyroid hormone in vivo during repair of full-thickness defects of articular cartilage. J Bone Miner Res 2000, 15:253-260.
56. Guilak F, Ratcliffe A, Lane N, Rosenwasser MP, Mow VC: Mechanical and biochemical changes in the superficial zone of articular cartilage in canine experimental osteoarthritis. J Orthop Res 1994, 12:474-484.

57. Schnabel M, Marlovits S, Eckhoff G, Fichtel I, Gotzen L, Vecsei V, Schlegel J: Dedifferentiation-associated changes in morphology and gene expression in primary human articular chondrocytes in cell culture. Osteoarthritis Cartilage 2002, 10:62-70.

58. Mueller MB, Tuan RS: Functional characterization of hypertrophy in chondrogenesis of human mesenchymal stem cells. Arthritis Rheum 2008, 58:1377-1388

59. Pelttari K, Winter A, Steck E, Goetzke K, Hennig T, Ochs BG, Aigner T, Richter W: Premature induction of hypertrophy during in vitro chondrogenesis of human mesenchymal stem cells correlates with calcification and vascular invasion after ectopic transplantation in SCID mice. Arthritis Rheum 2006, 54:3254-3266

60. Bian L, Zhai DY, Mauck RL, Burdick JA: Coculture of human mesenchymal stem cells and articular chondrocytes reduces hypertrophy and enhances functional properties of engineered cartilage. Tissue Eng Part A 2011, 17:1137-1145

61. Kafienah W, Mistry S, Dickinson SC, Sims TJ, Learmonth I, Hollander AP Three-dimensional cartilage tissue engineering using adult stem cells from osteoarthritis patients. Arthritis Rheum 2007, 56:177-187.

62. Jiang Y, Chen LK, Zhu DC, Zhang GR, Guo C, Qi YY, Ouyang HW: The inductive effect of bone morphogenetic protein-4 on chondral-lineage differentiation and in situ cartilage repair. Tissue Eng 2010, 16:1621-1632.

63. Steinert AF, Noth U, Tuan RS: Concepts in gene therapy for cartilage repair. Injury 2008, 39 Suppl 1:S97-S113.

64. Xian CJ, Foster BK: Repair of injured articular and growth plate cartilage using mesenchymal stem cells and chondrogenic gene therapy. Curr Stem Cell Res Ther 2006, 1:213-229

65. Wubbenhorst D, Dumler K, Wagner B, Wexel G, Imhoff A, Gansbacher B, Vogt $S$, Anton M: Tetracycline-regulated bone morphogenetic protein 2 gene expression in lentivirally transduced primary rabbit chondrocytes for treatment of cartilage defects. Arthritis Rheum 2010, 62:2037-2046.

66. Yazawa M, Sadaghiani AM, Hsueh B, Dolmetsch RE: Induction of proteinprotein interactions in live cells using light. Nat Biotechnol 2009, 27:941-945

67. Hundt W, Steinbach S, O'Connell-Rodwell CE, Bednarski MD, Guccione S: The effect of high intensity focused ultrasound on luciferase activity on two tumor cell lines in vitro, under the control of a CMV promoter. Ultrasonics 2009, 49:312-318.

doi:10.1186/ar4025

Cite this article as: Zhang W, et al: Inhibitory function of parathyroid hormone-related protein on chondrocyte hypertrophy: the implication for articular cartilage repair. Arthritis Research \& Therapy 2012, 14:221. 